From equation (2) is obtained

$$
\log \frac{\mathrm{d} U}{\mathrm{~d} t}=-\frac{\left(k_{1}+k_{2}\right) t}{2 \cdot 303}+\log k_{1} C_{1}
$$

which is the equivalent of Swintosky's equation (4) Thus

$$
k=k_{1}+k_{2} ; K=\log k_{1} C_{1}=\log k C_{0}
$$

Swintosky's specific velocity constant, $k$, is seen to depend on all processes of elimination in the same manner. $K$ enables a value of $C_{0}$ to be found and, used with $C_{1}$ and $k$, enables $k_{1}$ and $k_{2}$ to be estimated.

In fact, it is not possible to measure the rate of excretion, but only the average value, $E$, over a period, $T$. It is not difficult to show that if $E$ is used instead of $\mathrm{d} U / \mathrm{d} t, K$ becomes :

$$
\log \frac{C_{0}}{T}\{1-\exp (-k T)\}
$$

If the data on digitoxin are re-examined in this way, then $C_{0}=580 \mu \mathrm{gm}$.

Physics Department,

University, Hull.

JAMES HOUGH

\section{Hyperprotection against Radiation by combining Addition of Cysteine with Lyophilization}

By the addition of protective agents, such as broth and gelatin, it has become possible to obtain X-ray survival curves for phages in solution which are the same as those obtained from dry phages ${ }^{1}$, thus making it possible to interpret the results as being due to direct hits of the radiation on the phages. This attractive possibility has been rendered tenuous by the finding of hyperprotection by irradiating at low temperatures ${ }^{2}$ or by irradiating in the presence of agents such as cysteine ${ }^{3}$. Both these devices decrease the slope of the survival curves by a factor of about 1.4. The purpose of this communication is to present a technique which decreases the slope of the survival curve by a factor of about $2 \cdot 5$.

T2 coliphages in 4 per cent broth were frozen by being dropped into an aluminium cup standing in 'dry ice', and were irradiated with $100 \mathrm{kV}$. X-rays (half-value layer $2.0 \mathrm{~mm}$. aluminium) while at 'dryice' temperature. The cups were then placed in precooled test-tubes standing in a salt - ice bath (about $-20^{\circ}$ C.) and pumped through a manifold and a trap by a 'Highvac' pump. The preparations are pumped for $4-5 \mathrm{hr}$., which is about twice as long as needed to make them dry, as judged by eye. The preparations were reconstituted by being dropped into broth at room temperature and are then assayed.

The results of twelve experiments with broth and sixteen with $0.15 M$ cysteine added to the broth are

Table 1. Fractionat SURvival of T2r at Various X-RaY Doses (10,000 R./MIN.)

\begin{tabular}{|l|c|c|c|}
\hline & $0 \mathrm{~min}$. & $12 \mathrm{~min}$. & $24 \mathrm{~min}$. \\
\hline $\begin{array}{l}\text { Broth solution at } 0^{\circ} \mathrm{C} . \\
\text { Frozen, irradiation at }-78^{\circ} \mathrm{C} . \text { in } \\
\text { broth }\end{array}$ & 1.00 & 0.061 & 0.0041 \\
$\begin{array}{l}\text { Frozen, irradiation at }-78^{\circ} \mathrm{C} . \text { in } \\
\text { broth plus } 0.15 M \text { cysteine }\end{array}$ & 1.00 & 0.091 & 0.010 \\
$\begin{array}{l}\text { Frozen, irradiation at }-78^{\circ} \mathrm{C} \text { in } \\
\text { broth, dried at }-20^{\circ} \mathrm{C} .\end{array}$ & 1.00 & 0.11 & 0.017 \\
$\begin{array}{l}\text { Frozen, irradiation at }-78^{\circ} \mathrm{C} \text {. in } \\
\text { broth plus } 0.15 M \text { cysteine, dried } \\
\text { at }-20^{\circ} \mathrm{C} .\end{array}$ & 1.00 & 0.42 & 0.10 \\
\hline
\end{tabular}

given in Table 1. The survival due to other treatments is also given, by way of control experiments. That the increased survival is not due to the combination of the effects of cysteine and low temperature is clear, because preparations treated this way, but not dried, show a markedly smaller increase of survival.

The added effect due to the presence of cysteine is very probably not due to increase of concentration of cysteine due to sublimation, because the concentration used gives maximal protection in nonfrozen solutions. Accordingly, we have tentatively adopted the postulate that the protective action may be due to irradiated cysteine, which could be expected to be concentrated by the sublimation. If this postulate is adopted, the experiments offer evidence that the mechanism of protection is that of repair of damage to the phages, because the concentrated protector should be unable to get to the phages until the samples are again in solution; this is long after the radiation has done its damage.

This investigation was supported by research grant, $E-805$, from the National Microbiological Institute, National Institutes of Health, U.S. Public Health Service.

Brandeis University,

H. T. Epstein

D. SCHARDL

Waltham, Mass.

${ }^{1}$ Adams, W. R., and Pollard, E., Arch. Biochem. Biophys., 36, 311 (1952).

2 Bachofer, C. S., Ehret, C. F., Mayer, S., and Powers, E. L., Proc. U.S. Nat. Acad. Sci., 39, 744 (1953).

a Doermann, A. H., quoted in Watson, J. D., J. Bact., 63, 473 (1952).

\section{A Technique for One-Stage Bilateral Adrenalectomy in the Rabbit}

REPORTS of total adrenalectomy in the rabbit are indeed few in number ${ }^{1}$. In general, bilateral adrenalectomy in this species has been accomplished in two stages and has been attended by high mortality. We have been impressed by the desire of many investigators to utilize the totally adrenalectomized rabbit in experimental studies and with the fact that this desire has often been frustrated because of technical difficulties following one-stage adrenalectomy. Most workers are able to remove the left adrenal with ease, but attempts to excise the right adrenal gland, even at the hands of a skilled surgeon, often result in fatal |hæmorrhage from the vena cava. This occurs because the capsule of the right adrenal is connected to the adventitia of the inferior vena cava in this species.

The purpose of this communication is to present a technique for one-stage bilateral adrenalectomy in

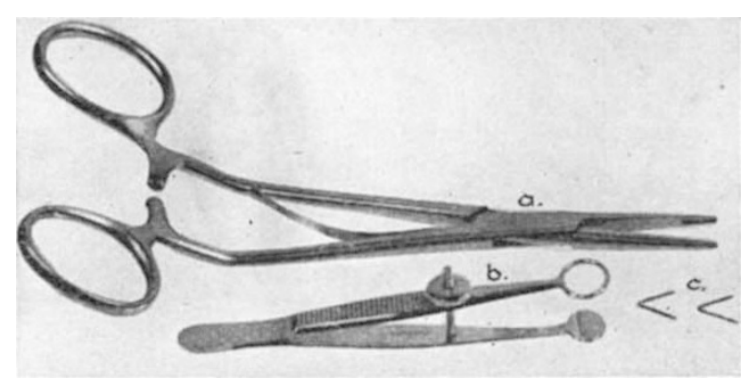

Fig. 1. Essential instruments for total one-stage adrenalectomy : (a) McKenzie brain clip applying forceps; (b) chalazion forceps ; 